\title{
Comparative Study of Errors of Documentation by Junior Residents in Medical Records of Patients, Who Died in Medical Intensive Care Unit of 1000 Bedded Teaching Hospital in Year 2014-2015
}

\author{
Authors \\ Vivek K. Pande $^{1}$, Aniket Saoji ${ }^{2}$, Jaydeep Nayse ${ }^{3}$ \\ ${ }^{1}$ Associate Professor, Dept of Medicine, NKP Salve Institute of Medical Sciences and Research Centre, \\ Nagpur, MS, India \\ ${ }^{2}$ Senior Resident, Department of Medicine, NKPSIMS \& RC, Nagpur, MS, India \\ ${ }^{3}$ Statisticians and In-charge Medical Record Section, NKP Salve Institute of Medical Sciences and Research \\ Centre, Nagpur, MS, India
}

\begin{abstract}
Aims and Objectives: To study errors of documentation by junior residents (JRs) and to compare error rates of year 2014 with year 2015.

Methodology: This study was interventional, record based, prospective, cross sectional study, with duration of two year from January 2014 to December 2015. After obtaining approval from Institutional Ethics Committee, a total of 222 death file of year 2014 and 240 death files of year 2015 of Medical intensive care unit(MICU) were obtained from Medical Record Department(MRD) of Lata Mangeshkar Hospital, Hingna, Nagpur. In the year 2015 regular monthly death audit meetings were conducted to overcome fallacies noticed in 2014. Data obtained was analyzed by chi square test.

Results: Statistically significant improvement was seen in parameters like daily revised treatment notes, name of Dead body $(D B)$ and death Certificate $(D C)$ receiver, procedure notes, Relation of $D B$ and $D C$ receiver with deceased, time of $D B \& D C$ handing over, daily progress notes, date of $D B \& D C$ handing over, senior review of USG/CT/MRI and signature of senior resident/lecturer on death summary.

Discussion: Error rates were reduced in 2015 as compared to 2014, which is attributed to detailed discussion of errors and proper training of JR's in medical record keeping.

Conclusion: Meticulous record keeping is needed to avoid observations from various agencies like consumer forum, insurance agencies and government health authorities and to improve health care provision in general. It is possible with proper training of junior residents.
\end{abstract}

Key Words: Record keeping, Error rates

\section{INTRODUCTION}

The medical records are systematic documents of a single patient's medical history and care across time within one particular health care provider's jurisdiction. The medical record includes notes of health care professionals including patient's medical history, observations, orders for the administration of drugs and therapies, investigations reports, etc. Medical records have given a lot of material for research work but have also became one of important evidence in court of law in medico-legal cases. With changing 
dimensions of doctor patient relations medical records has achieved great significance. Regarding methodology of record medical keeping, courts of law follow that "if it's not in medical record, it has not been done". ${ }^{[1]}$ First patient based record was used in the year 1907, and Standardization of records was first done by Tunbridge in 1965 and he also extracted information from it. Weed in 1968, proposed that medical records should be based on patient's problem rather than medical problem and it should be updated on daily basis. ${ }^{[4]}$ The Medical Council of India based on finding of Slapdash's on record keeping in India, has made it obligatory for every hospital attached to a medical college, to maintain medical records of patients in separate MRD. Medical records are of two types electronic and hand-written, later one being most commonly used in India. Handwritten records have certain fallacies like, they may be incomplete and inaccurate, they may be misfiled etc. Such lacunae can be overcome by computer based electronic records, but lack of trained personnel, infrastructure and it's cost is main hindrance to its swift practice. ${ }^{[3,5]}$ Irrespective of type of medical record, whether electronic or paper based or hybrid, a uniform and high veracity record keeping and coding policy should be adopted and revised and updated annually. Health care professionals should be educated to abide by all record keeping practice guidelines laid down by the institutions to improve quality, analysis of the data obtained from these medical records. ${ }^{[6]}$

Regular audits of records should be done to improve the quality of record keeping. Rectifications of lacunae should be done to avoid such fallacies. ${ }^{[7,8]}$ Medical record filled by physicians should include admission entry, follow-up and discharge entries, medical history, physical examination findings, diagnosis (both provisional and final), investigations advised/done, special entries like consent, unusual events, patient's information etc. reports of investigations, procedures done, treatment plan, progression/regression of patient following treatment. In case of invasive procedure/ general anesthesia is to be done all procedural checklists are to be fulfilled, duly signed consent form and report of pre-anesthetic checkup, completely filled forms. [3] In a nutshell, ideal medical record should be terse, precise, up-to-date, eloquent and internally unswerving. Documentation and record keeping are crucial to safeguard culpability, expedite synchronization of care between health professionals and for provision enhancement. ${ }^{[9]}$ It is important to find out the deficiencies/errors in documentation. But after exhaustive literature search, we could not find many studies, which focus on risk areas in a medical record, where mistakes are most commonly committed and interventions to reduce them. Therefore, the present study is one of the first of its kind to focus on above issues and hence carries weight age. Impact of death audit meetings in reducing errors in documentation has not been possibly reported till now.

\section{AIMS AND OBJECTIVES}

1. To study errors by junior residents (JR) in death files belonging to patients of MICU in years 2014 and 2015.

2. To compare error rates of year 2014 with year 2015.

\section{Inclusion criteria:}

Death files of patients of MICU of Lata Mangeshkar Hospital, Digdoh made available by Medical record section in calendar year 2014 and year 2015 were included.

\section{Exclusion criteria:}

1. Death Files of Medico Legal Cases

2. Brought in Dead cases

\section{MATERIAL AND METHODS}

This was a prospective, interventional, record based, cross sectional study, conducted in year 2014 and year 2015, after taking approval from Institutional Ethics Committee. Study duration was of two year. A total of 222 and 240 death files from year 2014 and year 2015 respectively were analyzed after screening them through inclusion and exclusion criteria. All the files were obtained 
from MRD, Lata Mangeshkar Hospital, Hingna road, Nagpur. Death files made available by medical record section were collected on monthly basis i.e. from Jan 2014 to December 2015. There were varieties of risk areas in which fallacies occurred on a regular basis which were identified through timely audits of medical records keeping practices and pre-validated from professors of different specialities and are listed below:

1. Name of patient on continuation sheets (CS).

2. Indoor Patient Department (IPD) number on CS.

3. Signature by JR's under daily notes.

4. JR's name below their signature.

5. Adequacy of admission notes.

6. Provisional diagnosis.

7. Notes of daily /revised treatment.

8. Notes of daily progress.

9. Notes of whole blood and blood product's transfusion.

10. Notes of procedures.

11. Consent for IPD care.

12. Written information of poor prognosis.

13. Consent for procedure.

14. Date and/ time in daily notes.

15. Senior review of ultrasonography (USG)/ computed tomography (CT)/ Magnetic resonance imaging (MRI).

16. Entry of reports of investigations in the charts.

17. Death notes.

18. Missing diagnosis.

19. Death summary.

20. Entry of reports of investigations done outside our hospital in CS.

21. Signature of senior physician on death summary.

22. Intake/ output charts.

23. Temperature, pulse, respiration (TPR) and blood pressure (BP) charts.

24. Signature of relatives on dead body and death certificate handing over certificate.

25. Name of relative on dead body and death certificate handing over certificate.
26. Entry of relation of the relative with the deceased on death body handing over certificate.

27. Entry of Date on dead body handing over certificate and death certificate handing over certificate.

28. Entry of time of dead body and death certificate handing over.

29. Numbering on all continuation sheets.

30. Investigations advised/done but report unavailable.

In the year 2015 regular monthly death audit meetings were conducted to overcome fallacies noticed in 2014. Data obtained was analyzed by chi square test.

\section{RESULTS}

(Table 1) A total number of 222 and 240 death files were studied in the calendar year 2014 and 2015 respectively. Total 7368 and 9771 sheets/notes from the year 2014 and year 2015 respectively from death files of MICU were analyzed for fallacies in documentation. In the year 2014 percentage of error was high for parameters like time of DB \& DC issue (86.49\%), numbering of continuation sheets (74.32\%), signature of senior resident on death summary (66.67\%), Relation of DB \& DC receiver with deceased receiving DB \& DC (50.0\%), Indoor patient department (IPD) number on sheets (48.79\%), name of DB \& DC receiver (42.79\%), date on DB \& DC handing over (40.99\%),\%), investigations advised and/or done but report not available in file $(35.59 \%)$, name of junior resident under signature on sheets (31.69\%), missing diagnosis $(25.68 \%)$. Error percentage was zero for blood transfusion (BT) notes $(0 \%)$, and error percentage was minimum for daily progress notes $(0.20 \%)$, Death summary $(0.45 \%)$, intake/output charts $(0.45 \%)$, TPR/BP charts $(1.80 \%)$.

In the year 2015percentage error was high for parameter like investigations advised and/or done but report not available in file $(35.83 \%)$, numbering of continuation sheets (33.33\%), 
consent for IPD treatment (23.08\%), provisional diagnosis (19.58\%), missing diagnosis (19.58\%), name of junior resident under signature on sheets $(15.72 \%)$ and signature of senior resident on death summary $(12.92 \%)$. Error percentage was zero for death summary $(0 \%)$. It was minimum for daily progress notes $(0.031 \%)$, daily revised treatment notes $(0.051 \%)$, procedure notes $(0.20 \%)$, blood transfusion notes $(0.552 \%)$ and intake/output charts $(0.833 \%)$.

Percentage errors were reduced in the year 2015 as compared to year 2014. Statistically significant improvement was seen in daily revised treatment notes $(97.27 \%)$ with $\mathrm{p}$ value of $<0.001$, name of DB \& DC receiver (95.13\%) with $\mathrm{p}$ value of $<0.001$, procedure notes $(93.39 \%)$ with $p$ value of
$<0.001$, Relation of DB \& DC receiver with deceased receiving DB \& DC $(93.33 \%)$ with $p$ value of $<0.001$, time of DB \& DC issue $(89.88 \%)$ with $\mathrm{p}$ value of $<0.001$, daily progress notes ( $84.92 \%$ ) with $\mathrm{p}$ value of 0.0005 , date of DB \& DC issue $(84.75 \%)$ with $\mathrm{p}$ value of $<0.001$, senior review of USG/CT/MRI (79.06\%) with $\mathrm{p}$ value of $<0.001$ and signature of senior resident on death summary $(76.88 \%)$ with $p$ value of $<0.001$. Other parameters which shows significant improvement were patient's name on sheets, IPD number on sheets, signature of junior resident on sheets, name of junior resident under signature on sheets, admission notes inadequacy, procedure notes, consent for procedure and date and/or time on notes.

TABLE 1: \% of documentation errors in risk areas in death files of Medicine department during calendar year 2014, with p-value

\section{STUDY PERIOD FROM JANUARY 2014 to}

\section{DECEMBER 2014}

$\%$ of documentation errors

PARTICULARS

No Patient's Name on continuation sheet/s

No IPD No. on Sheets

No Signature under notes

No Name under the sign.

No Admission notes inadequacy

No Provisional Diagnosis

No Daily/ revised Treatment notes

No entry of Daily Progress notes

Blood Transfusion notes error/s

Procedure notes error/s

No Consent for IPD treatment

No Poor prognosis information documentation

No Consent for procedure

No Date \&/or time entry in daily notes

No Senior review of USG/CT/MRI

$\mathrm{p}$ - value

1st quarter 2nd 3rd 4th 1 st -2 nd 1 st -3 rd 1 st-4th

$\begin{array}{lllllll}7.9 & 3.5 & 6.5 & 5.2 & 0.00020 & 0.22000 & 0.01000\end{array}$

$\begin{array}{lllllll}82.4 & 7.2 & 24.2 & 28.7 & 0.00000 & 0.00000 & 0.00000\end{array}$

$\begin{array}{lllllll}7.7 & 2.2 & 4.7 & 4.9 & 0.00000 & 0.00500 & 0.00900\end{array}$

$\begin{array}{lllllll}51.6 & 12.0 & 14.4 & 16.9 & 0.00000 & 0.00000 & 0.00000\end{array}$

$\begin{array}{lllllll}30.5 & 6.8 & 11.1 & 10.6 & 0.00000 & 0.00000 & 0.00000\end{array}$

$\begin{array}{lllllll}32.2 & 4.5 & 20.8 & 29.8 & 0.00000 & 0.00000 & 0.24000\end{array}$

$\begin{array}{lllllll}0.3 & 2.3 & 4.0 & 0.0 & 0.00070 & 0.00008 & 0.08000\end{array}$

$\begin{array}{lllllll}0.3 & 1.4 & 2.1 & 0.8 & 0.00700 & 0.00020 & 0.13000\end{array}$

$\begin{array}{llll}0.0 & 0.0 & 0.0 & 0.0\end{array}$

$\begin{array}{lllllll}2.3 & 1.5 & 0.5 & 0.0 & 0.19000 & 0.00060 & 0.00000\end{array}$

$\begin{array}{lllllll}42.4 & 34.1 & 0.0 & 14.9 & 0.00000 & 0.00000 & 0.00000\end{array}$

$\begin{array}{lllllll}5.1 & 2.3 & 4.2 & 6.4 & 0.00900 & 0.33000 & 0.21000\end{array}$

$\begin{array}{lllllll}6.2 & 0.0 & 1.9 & 0.0 & 0.00000 & 0.00001 & 0.00000\end{array}$

$\begin{array}{lllllll}5.4 & 3.2 & 8.2 & 3.1 & 0.01500 & 0.01200 & 0.01070\end{array}$

$\begin{array}{lllllll}37.3 & 11.4 & 29.2 & 10.6 & 0.00000 & 0.00010 & 0.00000\end{array}$

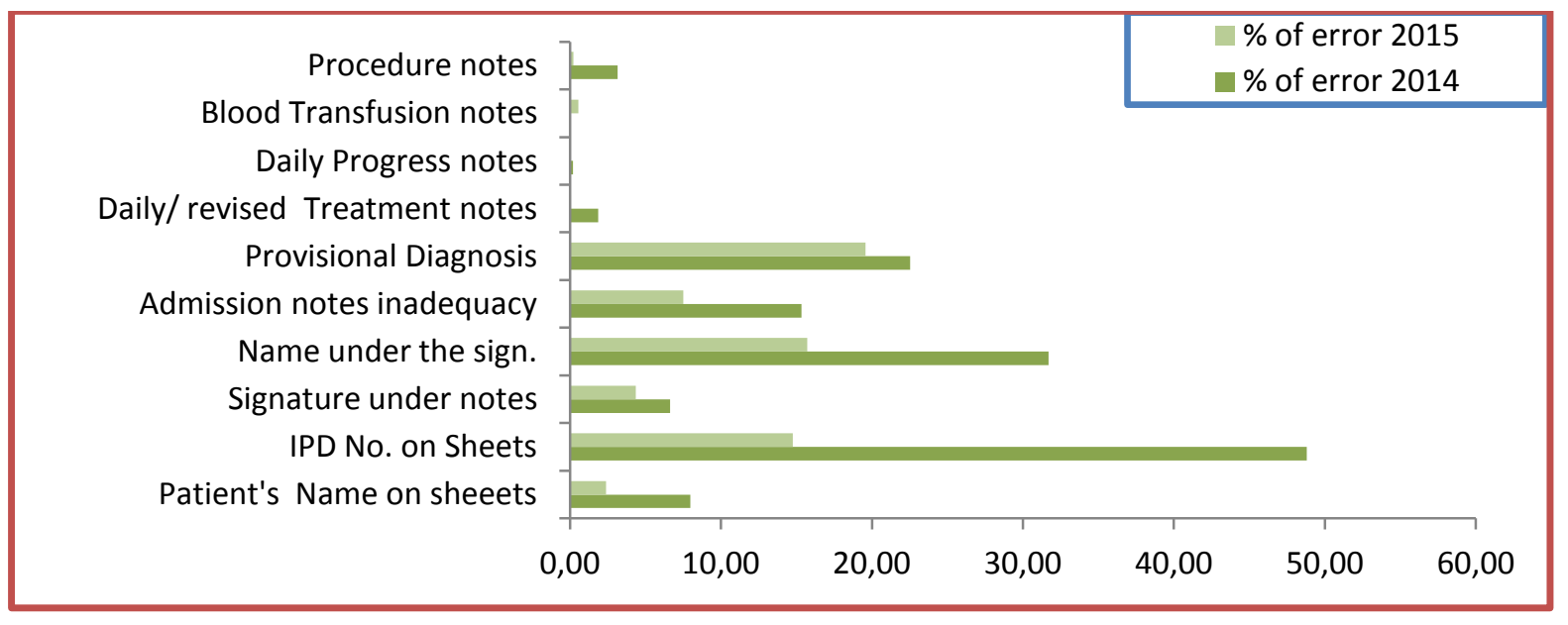



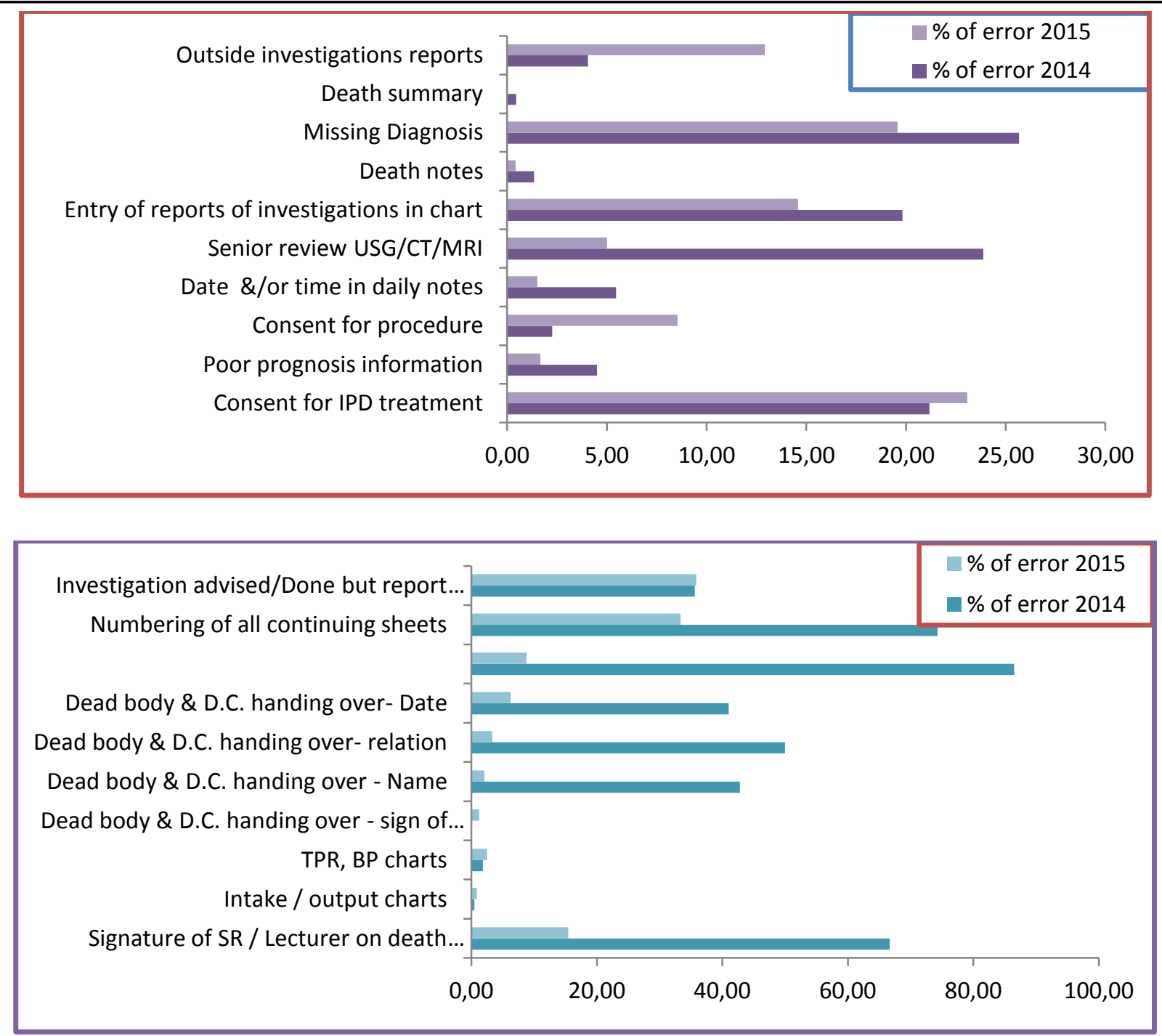

Above three graphs showing reduction of error rates

\section{DISCUSSION}

In this study, 30 risk areas where probability of repeated error was maximum were identified. While including each risk area in the list suitable justification was provided. Each continuation sheet should have patient's name and Indoor patient department (IPD) number on it, which helps to identify that the particular notes is of the particular patient. Signature and name of doctor under the notes helps to identify the treating physician. Admission notes are important as it helps in making the diagnosis. It is particularly more important in chronic diseases, in which patients chief complaints and examination findings may change in due course of illness. Provisional diagnosis is diagnosis made prior to confirmation with investigation and is based on adequate admission notes. Daily notes defines daily clinical course of the disease. Revision of treatment is very important as patients are treated with multidisciplinary approach. Daily notes and time and date on daily notes are vital since it justifies that in event of death, patient was regularly attended by the physician and appropriate treatment was given according to clinical and investigation report status of the patient and was monitored regularly. Blood transfusion notes are very important as transfusion reactions are common and sometimes are fatal. Sometimes blood transfusion reaction occurs because of mismatch transfusion which possibly occurs as a result of negligence. Procedure notes of each procedure are important as it helps to know the pre-procedure status of patient, intra procedure and post-procedure complications. It helps early identification of complications and 
helps to treat the complications on time. Consent for IPD admission, consent for procedure and poor prognosis information has legal and ethical significance. Investigations chart is required to access progress of the patient. It gives brief idea of investigations done in one go. It also serves as reserve report, in case original reports are misplaced during file movement Death files \&/ death summary are demanded by the police, courts to know the cause of death and adequacy of treatment or to prove negligence, if any. TRP, BP and intake/output charts support diagnosis, corroboration of deterioration and also serves as proof of adequate treatment, besides treatment book. Documentation of handing over of dead body and death certificate is particularly important from legal point of view. ${ }^{[10]}$.in the year 2015 there was improvement in some parameter attributed to regular monthly death audit. Statistically significant improvement was seen in daily revised treatment notes $(97.27 \%)$, name of DB \& DC receiver (95.13\%), procedure notes (93.39\%), Relation of DB \& DC receiver with deceased receiving DB \& DC (93.33\%), time of DB \& DC issue $(89.88 \%)$, daily progress notes (84.92\%), date of DB \& DC issue $(84.75 \%)$, senior review of USG/CT/MRI (79.06\%) and signature of senior resident on death summary (76.88\%). Other parameters which shows significant improvement were patient's name on sheets, IPD number on sheets, signature of junior resident on sheets, name of junior resident under signature on sheets, admission notes inadequacy, procedure notes, consent for procedure and date and/or time on notes. Surprisingly statistically significant deterioration was noticed in collection of outside investigation reports, exact cause of which is not known.

During the training of junior residents at our institute, they have been instructed to prepare and maintain medical records keeping in mind the following guidelines

1. Medical records should be unswerving and in no circumstances any manipulations be allowed
2. If at all, the changes are required to be done in the interest of patient, it should be done keeping original entry discernible avoiding scribble or use of white correction fluid over the original entry. The altered entry should be done legibly and signed with full name and designation of physician with date.

3. For such alterations in the records, appropriate and convincing reason should be mentioned.

4. Records should be sufficiently elaborated for complete understanding and clear meaning

5. Instructions appropriate only for patient care should be pointed out avoiding hypercritical remarks

6. As per policies of the institution, an identical formats should be used by all the health care professionals for keeping records in order to maintain the uniformity

7. Appropriate endorsement should be mandatory for release of facsimile of records

8. Billing and medical records should be maintained separately

9. All the records with attachments such as diagrams, laboratory test results, photographs and reports should be designated individually with name, age, sex and the unique registration number of the patient

10. All the records should be preferably written in black ink (to favour decipherable photocopying, if required in future) and with legible handwriting

11. All the entries should be done in real time mentioning accurate time and date with signature and full name of concerned health care professional

12. While treating the patient, if the health care professional observe any problem/risk and if he takes any action to correct that, it should be mentioned in the records

13. The records should never be fictitious 
14. The health care professionals should have good communication and information sharing skills for keeping accurate records which are important for referrals and handover

15. As per the legal requirements and institutional policies, the confidentiality of the records should be maintained

16. It is recommended to follow ALCOA acronym (attributable, legible, contemporaneous, original and accurate) for a better documentation

17. Records should be kept securely but accessible when required

18. If the dosage or dosing schedule of the medicaments are modified, the reason for the change should be entered in the record with modified dose or dosing schedule

19. The entries made by students should be verified and corrected by the senior physician with his counter signature

20. All entries should be concomitant and sequential with no space vacant in between as it may give an impression that the space is left vacant or later entries

21. The mislaid information in handwritten records should be amalgamated appropriately within the record and not as supplementary sheet or attachment. If the records are in electronic format, it should be done by adding the heading as 'Addendum' followed by date and time of omission and addendum.

Negligence suits are an important aspect in record keeping as it can be produced as evidence in courts of law. Incomplete documentation is most common error made by physicians in record charts. Many times despite of adequate and appropriate treatment given doctors fail to document the full extent of their treatment or forget to include what was discussed with patient. This is classically presented as negligence, by patient's lawyer in courts of law. Therefore one must be highly diligent in maintaining complete and accurate records. ${ }^{[1,3,11,12,13,14]}$ Most of the physicians bypass the importance of medical record. Majority of them are not fully aware of the conventions prevailing the accomplishment of the patient health record or its importance as a legal document that can be demanded by the courts of law, as evidence. This finding can be traced back, in some extent in to the lack of focus on this issue in medical colleges. This negligence towards good record keeping continues through the internship and residency phase of medical training, and there is literally no education to demonstrate its importance and procedures to for good record keeping. As a result, at majority of times, medical records are found to be inaccurate and incomplete. The significance of comprehensive and accurate health records lies in the fact that all health care providers for patient, be it in present or future hospitalization, will have access to all relevant data for patient's prime care. ${ }^{[15,16,17,18,19]}$

\section{CONCLUSION}

The habit of proper documentation in IPD files can be imparted during junior residency period in a teaching hospital. Therefore it is recommended that monthly death audit may be conducted in all teaching hospitals and medical colleges, so as to overcome fallacies in documentation and to rectify errors. Death audit at regular interval will keep treating physician vigilant for good record keeping practice. Good record keeping practices should be inculcated right from undergraduate days of physician's training. Since present study is one of the first of its kind, conducting similar studies will help to identify more risk areas. Findings of such studies will help to formulate and implement national guidelines for good documentation.

\section{REFERENCES}

1. Medical Record Administration and Healthcare Documentation, Rapid Action Revision (RAR) Issue, retrieved from http://www. apd.army.mil/pdffiles/r40_ 66.pdf[last updated on 4/02/2010].

2. CG2-Record Keeping Guidelines, retrieved from http:/ www. 
nhsprofessionals.nhs.uk/download/comms/ cg2\%20-\%20record\%20

keeping\%20clinical\%20guidelines.pdf.

3. Tiwari S. Record keeping In Textbook of Medico-legal Issues Related to Various Medical Specialities editor Nilofer Mujawar, Jaypee brothers medical publishers, New Delhi 2012: 49-52.

4. Weed L. Medical records that guide and teach. N Engl J Med 1968; 278:652-7.

5. Nursing documentation, record keeping and written communication, Elsevier Health retrieved from https:// www.us.elsevier.health.com/media/us/sam ple chapters/9780443073991/9780443073991.pdf.

6. "Statement on Consistency of Healthcare Diagnostic and Procedural Coding."AHIMA Position Statement, retrieved from www. ahima.org. [last updated on December 2010].4

7. "Developing a Coding Compliance Policy Document (Updated)." Journal of AHIMA, retrieved from www.ahima.org. [Updated on March 2010].

8. Cassidy BS. Defining the core clinical documentation set for coding compliance, retrieved from http://library.ahima.org/expedio/groups/public/documents/ahima/bok 1 049822.pdf.

9. Dimond B. Legal aspects of documentation. Exploring common deficiencies that occur in record keeping. British Journal of Nursing 2008; 14(10):568-71.

10. Bodek H. Basic Standards for Clinical Documentation and Record Keeping, The New York State Society for Clinical Social Work, Inc. downloaded from http://www. clinicalsw.org/basic_standards.html.

11. Bargaje C. Good documentation practice in clinical research. Persp Clin Res 2011;2(2):59-63.
12. Health care records- documentation and management, retrieved from http://www0.health.nsw.gov.au/policies/pd /2012/pdf/ PD2012_069.pdf.

13. Legal Medical Record Standards, retrieved from http://policy. ucop.edu/doc/1100168/ Legal Medical Record.

14. A Guide to Better Physician Documentation, retrieved from http://www.health.gov.on.ca/transformatio n/providers/information/pdf/guide_bpd.pdf

15. Roach JR, William H. Medical Records and the Law, 3rd ed, Aspen Health Law and Compliance Centre;1998:30-32.

16. Sinha S, McDermott F, Srinivas G et al. Use of abbreviations by health care professionals: what is way forward? Postgrad Med J 2011;87(1029):450-2.

17. Carroll AE, Tarczy-Hornoch P, O'Reilly E et al. Resident documentation discrepancies in a neonatal intensive care unit. Pediatrics 2003;111(5.1):976-80.

18. Hameed F. Are there any approved medical abbreviations? $\mathrm{Br}$ Med J;2012:344.

19. Saraliya PK, Satish NT, Harish S. Consumer Protection Act and Medical negligence; an update. Journal of Indian Medical Association 2009;111(7):468-71. 